\title{
BRUJAS, LIBROS Y CINTAS DE VÍDEO: LITERATURA EN TORNO A LOS JUICIOS DE SALEM ${ }^{1}$
}

\author{
Roberto Morales Estévez \\ ESERP Madrid \\ prof.rmorales@eserp.com
}

\section{Brevísima Relación del estallido de La GRAN CAZA De Brujas en SALEm (1691)}

finales del siglo XVII, la colonia de Salem había conseguido dominar el
agreste Nuevo Mundo. Para ello tuvieron que ser enormemente colabora-
tivos y observar una férrea disciplina para crear una comunidad teocrática de santos invisibles que integrarían una iglesia universal (Golubov 2004: 45). Los esforzados habitantes de Salem quisieron comenzar a disfrutar del bienestar por el que habían luchado, y la rígida moral del gobierno teocrático, que clamaba contra la relajación de las costumbres, comenzó a ser un estorbo para sus convecinos. Este poder, además, se vio socavado por el Fuero de Massachusetts de 1694, por medio del cual se permitía el voto a los terratenientes blancos no puritanos.

Tiempos revueltos se vivían en la colonia, que por espacio de tres años y hasta 1692 no contó con un gobierno e instituciones operativas. Este hecho dejó las escrituras de propiedad sin validez legal alguna, lo que se tradujo en un continuo enfrentamiento judicial entre los vecinos por las lindes de sus tierras. A esta tensión entre granjeros debemos unir el enfrentamiento entre Salem y Salems Farm. La primera se fundó en 1626 como puerto comercial y la segunda lo hizo a su lado para abastecer a la primera. El choque tuvo dos familias líderes claras. Mientras que los comerciantes se reunieron en torno a la familia de los Porter, los terratenientes lo hicieron en torno a los Putnam.

\footnotetext{
1 Este artículo se ha desarrollado en el marco del grupo de investigación «Mentalidades mágicas y discursos antisupersticiosos (siglos XVI, XVII y XVIII)», reconocido oficialmente en la Universidad Autónoma de Madrid.
}

Edad de Oro, XXXVII (2018), pp. 228-246, ISSN: 0212-0429 - ISSNe: 2605-3314 
La ruptura entre comerciantes y terratenientes era total, llegando al extremo de que estos últimos buscaron independizarse de los habitantes del puerto, dados sus dispares intereses económicos y modelos sociales. En 1672 la comunidad religiosa saltó por los aires cuando los Putnam llamaron a un ministro para que dirigiera un templo solo para su facción. Dicho ministro, el señor Parris, llegaría a Salem acompañado de su esposa, de su hija Betty, su sobrina Abigail y su esclava antillana Tituba. Casi todos actores principales de la histeria colectiva que posteriormente se desencadenó en Salem. Boyer (1972) y Nissenbaum (1974) afirman que lo que subyacía en las acusaciones de brujería de Salem era un arraigado conflicto social que se expresó, en último término, en la caza de brujas de 1692. Por su parte, Levack (1995: 259-260), sin dejar de lado las causas socioeconómicas, incide en las tensiones religiosas y en el sistema teocrático que se practicaba en Nueva Inglaterra.

Como refleja Bosch (1984: 74), la chispa que dio lugar a la gran caza de brujas de Salem fue algo tan pueril como un juego amoroso llevado a cabo por un grupo de chicas en edad casadera. Estas eran: Ann Putnam — de doce años-, Mary Wolcot — de dieciséis —, Elizabeth Hubbard — de diecisiete-, Abigail William - de once - Mary Warren - de veinte - y Mercy Lewis - de diecinueve años- El grupo de chicas se entretenía hablando de los jóvenes que conocían e intentaban adivinar su futuro amoroso mediante un simple juego que ellas mismas habían inventado, consistente en una especie de bola de magia con una clara de huevo en su interior. En ella un día las chicas creyeron ver un ataúd, presagio de muerte, lo que les llevó a tener actitudes neuróticas y a adoptar posturas lascivas y vehementes discursos, ante el asombro de sus padres.

El reverendo y juez de Salem, Hale, escribiría una obra en 1697, que no vería la luz hasta después su muerte en 1702, en torno a los juicios de Salem llamada $A$ Modest Inquiry into the Nature of Witchcraft donde nos relata el inicio del caso. Hale creyó en un principio que el demonio estaba detrás de todo aquello (Espejo 2011: 52-55), pero rápidamente empezó a denunciar las más que evidentes irregularidades que se estaban llevando a cabo:

En los últimos meses del año de 1691, el señor Samuel Parris, párroco de la iglesia del pueblo de Salem, vio a una hija suya de nueve años y también a una sobrina de la edad aproximada de once años, tristemente afectadas por extrañas dolencias. Y solicitó la intervención de los médicos, si bien las niñas empeoraron. Y finalmente uno de los médicos manifestó la opinión de que sufrían maleficio. Los vecinos aceptaron al punto esta opinión y concluyeron que estaban embrujadas (Howe 2016: 329-330).

Como dice Miller en la obertura de su obra El Crisol, la brujería se convirtió en la excusa perfecta para liberar demonios humanos, demasiado humanos: 
Vecinos que llevaban odiándose durante mucho tiempo podían ahora expresar abiertamente lo que sentían y además vengarse, a pesar de las caritativas advertencias de la Biblia. El ansia por poseer más tierras, que antes quedaba patente en constantes rencillas sobre las lindes y los testamentos, se elevaba ahora al coso de la moral. Era posible acusar de brujería al vecino y encima sentirse plenamente justificado. Podían salvarse viejas deudas en el contexto de un combate celestial entre el Señor y Lucifer; los recelos y la envidia de los miserables frente a los más prósperos podían, y de hecho así sucedió, estallar y formar parte de esa venganza colectiva (Miller 2011: 119).

\section{LITERATURA PARA UNA CAZA DE BRUJAS}

La caza de brujas de Salem debemos entenderla como la última victoria del cazador de brujas más famoso y sanguinario de Inglaterra: Matthew Hopkins. Este hombre, sin apoyo formal del parlamento inglés, pero con ayuda de las autoridades locales, recorrió en la década de los cuarenta del siglo xVII la región de Essex y alrededores buscando pruebas de brujería. De esta región inglesa salió la primera oleada de colonos rumbo a América y con ellos viajó una visión del mundo donde se producía un enfrentamiento eterno y feroz entre Cristo y Satanás. La región de Nueva Inglaterra recibió esta influencia inglesa de manera mucho más poderosa que Nueva York, Nueva Jersey, Delaware, Maryland o Virginia donde, o no se produjo caza de brujas alguna o, de hacerlo, fue mucho más comedida.

Es imposible entender el fenómeno de la caza de brujas sin acudir a la literatura que le dio cobertura ideológica, los manuales de inquisidores. El primero de ellos fue el Malleus maleficarum o Martillo de las brujas, publicado en 1486 y escrito por Heinrich Krämer y Jacob Sprenger. Dicho manual reflejaba la nueva visión de la brujería por parte de la Iglesia, que ya había sido expuesta en la famosa bula promulgada en 1484 por Inocencio VIII, Summis desiderantes affectibus, visión que, como asevera Clarck en conversación con la doctora Tausiet (2010), no difería mucho de la protestante:

En términos de demonología formal, era muy poco lo que diferenciaba a las dos principales religiones de la Edad Moderna. Tanto los protestantes como los católicos decían cosas muy parecidas sobre los demonios y sobre la brujería. Esto se debe a que los modelos de pensamiento y los hábitos lingüísticos que regían las representaciones de la demonología y la brujería procedían de tradiciones cosmológicas, teorías de la comunicación y estrategias evaluativas que trascendían las diferencias religiosas.

En lo que sí diferían protestantes y católicos era en el mayor interés mostrado por la demonología por parte de los primeros (Zamora Calvo 2016: 133). Rápidamente se asoció la figura del papa a la del Anticristo dentro la lucha teológica que planteó la reforma luterana, que además, al rechazar la validez del exorcismo y de 
la confesión privada, dejaba al fiel protestante más desprotegido frente a la amenaza demoniaca, por lo que el miedo a su poder se hizo más opresivo. Lutero, que reconoció mantener conversaciones diabólicas en su obra Charlas de sobremesa (1531-1546), opinaba que el demonio habitaba en el cuerpo de los herejes, los sediciosos, las brujas, los usureros o las prostitutas, aunque también podía engañar al fiel haciéndose pasar por ángel o el mismo Dios; un demonio al que Lutero hacía además responsable de la peste y otras enfermedades.

El Malleus maleficarum no era el manual ni más completo ni más vendido de la época, siendo superado por el Tractatus de Hereticis et Sortilegiis que el juez papal Paulus Grillandus publicó en 1524 (Levack 1995: 85-86); pero, sin lugar a dudas, es el que más influencia ejerce a lo largo de los siglos. Como refleja Zamora Calvo (2002: 1888), «el Malleus maleficarum ejerce una autoridad imprescindible. De ahí se comprende la enorme difusión que adquiere esta obra en Europa, lo que también queda testimoniado a partir de sus numerosas ediciones».

Levack nos anunciaba líneas más arriba las grandes similitudes que había entre la demonología católica y protestante, y es que el Malleus no solo ejerció su magisterio entre los católicos, dejándose notar su influencia en los tratados demonológicos protestantes. Dichas similitudes pueden comprobarse en la obra del pastor protestante Tomas Cooper, The Mistery of Witchraft, escrita más de 130 años después, en 1617. Se trata de la experiencia directa del pastor en los procesos judiciales contra hechiceros a los que tuvo acceso mientras que estuvo en Cheshire y que compiló en el volumen citado. Aunque no mencione en ningún momento la obra del dominico, las similitudes son evidentes, lo que le llevan a concluir a Méndez (2018: 327) que:

La común utilización de vocabulario técnico y una construcción argumentativa muchas veces extremadamente similar puede permitirnos pensar que los demonólogos ingleses se inspiraron en los escritos de sus rivales confesionales, mucho más de lo que estaban dispuestos a reconocer con una cita o una mención [...] son modos particulares de expresar un acervo común de ideas en desarrollo desde los inicios mismos del cristianismo.

Por supuesto, el libro de Cooper no fue el único. Podemos citar las obras del predicador de Essex George Gifford, A Discourse of the Subtill Practises of Deuilles by Witches an Sorceres (1587) y A Dialogue Concerning Witches and Witchcrafts (1593). Del eclesiástico Richard Bernard destacamos la obra A Guide to Grand Jury-Men (1627) o el tratado del demonólogo inglés William Perkin, Discourse of the Damned Art of Witchcrafts (1608). Obras que son comparadas en un anterior trabajo del ya citado Méndez (2015). La investigadora especializada en Salem, Elizabeth Howe (2014: 85-86), pone precisamente en manos del ministro Parris un ejemplar de la obra de Perkins. Como este último extremo es imposible de 
aseverar a día de hoy, la investigadora concluye que: «Si bien es imposible certificar con total precisión la coincidencia de que Parris tuviera en aquel momento un manual que hablaba de la caza de brujas, el amplio alcance de los escritos de Perkins no está en cuestión».

Por tanto, tanto las obras católicas como las protestantes que se utilizaron en Salem acudieron al concepto acumulativo de brujería propuesto por Levack (1995: 53-78). Participa de este concepto la creencia en el diablo, con toda la lucha teológica que sobre él se sigue teniendo, aunque la idea central es el pacto demoniaco. Por medio del pacto, los demonólogos creaban la base de la definición legal de brujería a la vez que establecían el vínculo entre la práctica del maleficium y el culto al demonio. Así podemos leerlo en las actas judiciales de Salem en la declaración de la esclava antillana Tituba:

[P.]: ¿Qué pacto hiciste con ese hombre que fue a ti? ¿Qué te dijo? / [R.]: Me dijo que era Dios y que debía de creer en él y servirlo por seis años y me daría muchas cosas bonitas./ [...] / Entonces dije esto. Le dije que no creí que fuera Dios. Le dije que iba a buscar a mi amo, y quise subir, pero él me agarró y no me dejó ir. [...] / [P.]: ¿Te pidió que lo sirvieras la primera vez o también la segunda? / [R.]: Sí. Volvió a pedírmelo. Y que lo sirviera por seis años y la segunda vez [ilegible] y me enseñó un libro. / [P.]: Y ¿cuándo fue eso? / [R.]: El viernes siguiente y me enseñó un libro de día, por la mañana temprano. / [P.]: Y ¿qué libro era? ¿Grande o pequeño? / [R.]: No me lo enseñó sino que lo llevaba en el bolsillo [ilegible] / [P.]: ¿No te hizo escribir su nombre? / [R.]: No, entonces no porque mi ama me llamó a la otra habitación. / [P.]: ¿Qué te dijo que hicieras con el libro? / [R.]: Me dijo que escribiera mi nombre en él. / [P.]: ¿Lo escribiste? / [R.]: Sí. Solo que le hice una marca en el libro y la hice rojo como la sangre. / [P.]: ¿La sacó de tu cuerpo? / [R.]: Dijo que la sacaría la próxima vez que viniera. Me dio un alfiler atado a un palo, pero no me dejó que me hiciera sangre todavía, sino que era para cuando volviera la próxima vez².

La idea de pacto ya se encuentra en los textos de san Agustín y fue potenciado por el escolasticismo, distinguiendo además entre pacto explícito e implícito. El otrora mago poderoso dominador de demonios pasaba a convertirse en un simple brujo, hereje y apóstata, engañado por el demonio.

La gran caza de brujas habría sido mucho menor sin la existencia de la idea del aquelarre ${ }^{3}$, que no se estableció de manera definitiva hasta el siglo xv. Una

2 Declaraciones de Tituba realizadas entre el 1 y 2 de marzo de 1692 (Howe 2016: 237-239). Pueden consultarse las actas originales en: Salem Wich Trials Documentary Archive ans Trasncripttion Project $<$ https://at.virginia.edu/2wAe4r9>.

3 Sin lugar a dudas uno de los libros más interesantes sobre el aquelarre es Ginzburg (2003). Para desenmarañar el esquivo término de «aquelarre», es imprescindible acudir a Azurmendi (2012: 42-53) y Henningsen (2012: 56-65). 
antisociedad que se reunía en los bosques en mitad de la noche para adorar al diablo, mancillar los símbolos del cristianismo y realizar orgías, bailes y banquetes caníbales con carne de infantes. Con ello subvertían las normas morales y sociales más elementales de la sociedad y ponían en peligro el orden establecido.

El último gran ingrediente del concepto acumulativo de brujería es precisamente el que tiene raíces más puramente populares. Nos referimos al vuelo, idea que la élite descartó hasta que algunos autores así lo afirmaran en sus escritos, como el juez secular Lancre en su obra Descripción de la inconstancia de los malos ángeles o demonios (2004 [1613]: 104):

El Diablo las transporta al Sabbat montadas en bastones sobre escobas, o en el propio Diablo en forma de macho cabrío, de asno, de caballo o de algún otro animal. Los bastones están ungidos con algún ungüento o grasa, fabricado con grasa de algún niño al que han asesinado, sin que nunca hayamos podido descubrir si se trata del mismo ungüento y está fabricado con los mismos ingredientes que el que utilizan como veneno; sobre aquél hemos descubierto y conocido mucho mejor sus ingredientes que sobre éste último; y los propios libros no nos han podido enseñar nada al respecto.

La creencia en el vuelo ya podemos rastrearla casi un siglo antes en la obra del español Martín de Castañega, en su Tratado de las supersticiones y hechizerías y de la possibilidad y remedio dellas (1529 [1994]), en su «Capítulo sexto. De cómo los consagrados al demonio pueden andar por los aires», donde se percibe el debate que en torno al vuelo de las brujas se estableció entre especialistas:

Muchos dudan si los bruxos andan, como dizen, por los ayres y mares muchos doctores dixeron que no. Para esto han de notar esta regla. Sabiendo que ello es posible y que alguna vez se ha visto y se prueua por la escritura, lo mesmo o semejante a ello y las mesmas personas del demonio engañadas lo confiesan ser assi, ninguna razon hay porque no sean creídas.

Sorprende que Tituba coincidiera con tan ilustres demonólogos en sus declaraciones:

[P.]: ¿ Cómo fuiste? ¿En qué montas?

[R.]: Monto en un palo o una pértiga, y Good y Osburn vienen detrás de mí. Vamos agarradas las unas a las otras y no sé cómo vamos. Pues no vi ni árboles ni camino sino que enseguida de subir habíamos llegado (Howe 2016: 234).

Otra creencia popular que nunca se integró plenamente en el concepto de brujería es el de la metamorfosis, la capacidad de los humanos para convertirse en animales. Como indica Levack (1995: 78-79), incluso los crédulos autores del 
Malleus maleficarum dudaban de este extremo apoyándose en la tradición que lo consideraba una ilusión del demonio, lo que no impidió que se sentenciara como brujas a varios lobos. A diferencia de lo que ocurría en Europa, en Salem los animales que se citan en los procesos, como gatos rojos o verdes, un pájaro amarillo o un gran perro negro, lo hacen como servidores del demonio. Volvamos a escuchar a la esclava Tituba en su declaración:

[P.]: ¿Qué otras criaturas has visto? [...] / [R.]: Un pájaro amarillo. / [P.]: ¿Dónde? / [R.]: Con el hombre que tiene cosas bonitas. / [P.]: ¿Qué otras cosas bonitas? / [R.]: Aún no me las ha enseñado, pero me dijo que me las enseñaría mañana y me dijo que si lo servía me regalaría un pájaro. / [P.]: ¿Qué otras criaturas viste? / [R.]: Vi dos gatos: uno rojo y uno negro y grande como un perro pequeño. / [P.]: ¿Qué hacen esos dos gatos? / [R.]: No lo sé. Los he visto dos veces. / [P.]: ¿Qué te dijeron? [R.]: Que los sirviera [...] / [P.]: ¿Das de mamar a esos gatos? / [R.]: No, nunca lo he hecho. No les dejé y por poco me arrojaron al fuego. / [P.]: ¿Cómo haces daño a los que pellizcas? ¿Pides a esos gatos o a otras cosas que lo hagan por ti? Dinos, ¿cómo se hace? / [R.]: El hombre me envía los gatos y me pide que los pellizque [...] (Howe 2016: 232-233).

Con las declaraciones de la india Tituba, esclava del señor Parris, a la que Fernández Juárez (2016) le ha dedicado recientemente un interesante estudio, hemos podido constatar que las ideas de los demonólogos estaban en boca de los acusados en Salem. Ahora bien, que una mujer de los Barbados manejara dichos conceptos es algo muy poco probable. Como refleja Howe (2016: 229-230), las confesiones de Tituba denotan un preciso conocimiento de la brujería inglesa y de sus manuales de demonología, conocimientos académicos que eran totalmente ajenos a la cultura popular, lo que parece indicar que la mujer fue coaccionada en su confesión y que se le dictó lo que debía decir. A su vez, las confesiones de Tituba, además de demostrar la presencia de manuales de demonología en Salem, apoyan la tesis de la importancia de dicha literatura para cimentar una caza de brujas.

Un concepto específico en la caza de brujas de Salem fue la evidencia espectral o spectral evidence, la prueba definitiva para identificar a una bruja. Se suponía que la bruja o brujo acudía como espectro a atormentar a su víctima lo cual, lógicamente, era muy difícil de demostrar. Con la discusión sobre la realidad de ello se abría un debate teológico sobre si el Diablo podía o no adoptar el aspecto de una persona inocente. A la postre, sería esta disputa intelectual sobre la prueba espectral lo que terminara por detener la paranoia brujeril. El debate dejó a su vez una interesante literatura como la obra de Increase Mather, Cases of Conscience Concerning Evil Spirits, publicada un mes después de las últimas ejecuciones en Salem. En su escrito, Mather analizaba la prueba espectral para concluir que la misma no era un método fiable para identificar a supuestas brujas. No sería el 
único, el comerciante de Boston Thomas Brattle, casi al mismo tiempo que Mather, publicó una carta en que ponía en cuestión los métodos del Tribunal Especial de Audiencia y Chancillería a la vez que dudó sobre la evidencia espectral (Bratlle 1692: 169-176).

La aparición de estos dos textos obligó al gobernador William Phips a disolver el tribunal el 29 de octubre de 1692, lo que no acabó con la literatura que rodeó la caza de brujas de Salem ni con el debate de la prueba espectral. Cotton Mather, hijo de Increase, publicaría en 1693, Wonders of the Invisible World, donde, a diferencia de su padre seguía apoyando la evidencia espectral y la realidad de la brujería. El fin de Salem no significó que la creencia en la brujería desapareciera, a pesar de que en 1697 el jurado de Salem pidió disculpas, sino que los jueces serían más cautos a la hora de inculpar a alguien por el delito de brujería. El reverendo y juez de Salem, John Hale, que en una obra publicada en 1702 tras su muerte, Modest Enquiry into the nature of Wichtcraft, pedía perdón a Dios por el sufrimiento infligido a personas inocentes por motivos como la venganza, que se produjeron según el reverendo por la tendencia al error de la condición humana y el estado de psicosis en el que se celebraron los juicios. La caza de brujas de Salem era ya historia.

\section{El renacer de Salem: El crisol de Arthur Miller}

Bien parece que la literatura rodea a Salem y sus protagonistas. Es de sobra conocido que Nathaniel Hawthorne, autor de una de las novelas cumbre de la literatura norteamericana del siglo xIx, The Scarlet Letter (1850), era descendiente del juez acusador de Salem, John Hawthorne. También en el xIX se publican las obras de Henry Wadsworth, Longfellow Giles Corey of the Salem Farms (1868), y de Mary E. Wilkins Giles Cory, Yeoman (1892-1893), entre otras. Pero sin lugar a dudas la obra que más repercusión ha tenido es la obra de Arthur Miller, El crisol (1953). Una obra que ha vendido millones de ejemplares por todo el mundo, que no cesa de representarse, del que se dice que es uno de los textos dramáticos más importantes del siglo xx (Espejo 2011: 61) y que destaca, como veremos, por su carácter universal y atemporal. En dicho texto nos vamos a centrar y el mismo es indisociable, como cualquier obra por otro lado, del momento histórico en que es producido.

Aunque asociamos el término "caza de brujas» a la Guerra Fría y al Macartismo, lo cierto es que ya en 1919 se produjo un episodio que puede calificarse así, cuando el fiscal general A. Mitchell Palmer comenzó a arrestar a cualquier sospechoso o a registrar domicilios sin orden judicial alguna. Además, como sus antecesores en Salem, no dudó en aplicar la tortura e incluso la ejecución de algunas personas por delitos jamás demostrados (Espejo 2011: 27). 
La histeria anticomunista volvería a activarse en 1938 con la creación de la House Un-American Activities Committe (HUAC), supuestamente creada para luchar contra actividades subversivas de, principalmente, nazis y antisemitas, pero que se centró desde sus inicios en la actividad de los comunistas. Sospechoso era cualquiera que estuviera relacionado con el mundo de la cultura y la intelectualidad, ya fuese profesor universitario, alumno o escritor. Sin lugar a dudas la caza más famosa se produjo en el mundo del cine. En 1944 se fundaría la Motion Picture Alliance of the Preservation of American Ideals (MPAPAI), liderada por el realizador Sam Wood, contando con miembros tan ilustres como Walt Disney. Su manifiesto fundacional, publicado en la revista Variety, dejaba muy claras sus intenciones:

\begin{abstract}
Nos preocupa el hecho de que nuestro sector específico, el cine, se vaya afirmando la impresión de que la industria está compuesta y dominada por los comunistas, extremistas de izquierdas y otros individuos de la misma calaña [...]. Nosotros nos comprometemos a repeler, con todos los medios de los que disponemos, cualquier intento que amenace la fidelidad del mundo de la pantalla a los ideales de la América Libre, puesto en práctica por individuos o grupos organizados (Riambau 1996: 86-87).
\end{abstract}

En este clima de histeria se constituiría en octubre de 1947 una comisión parlamentaria presidida por el ultraconservador congresista de Nueva Jersey J. Parnell Thomas, contando en su equipo con, entre otros, el futuro presidente de Estados Unidos Richard Nixon. Los guionistas y escritores inculpados, conocidos posteriormente como los «diez de Hollywood», habían cometido el único delito de ser simples militantes de izquierdas. Realmente fueron muchas más de diez las personas inculpadas; el dramaturgo y poeta Bertolt Brecht se vio obligado a comparecer ante una la comisión que además manejaba una interminable lista negra con nombres tan ilustres como Luis Buñuel, Charles Chaplin, Orson Welles o Leonard Berstein. Todas personas comprometidas como la guionista Lilian Hellman, que con una actitud «inamistosa», como calificó la comisión a los inculpados que no colaboraban, declaró: «I cannot and will not cut my consciencie to fit this year's fashions» (Espejo 2011: 38).

Mientras, otros actores, como Ronald Reagan, aplaudían la limpieza ideológica que se estaba llevando a cabo en el cine. Walt Disney, como testigo amigable, llegaría a declarar ante la comisión: «no creo que el Partido Comunista sea un partido político. Creo que es una cosa antiamericana». Lela Rogers, madre de Ginger Rogers, afirmaría ante la comisión: «es imposible que los ciudadanos americanos puedan ser comunistas. No lo creo ni yo misma. No lo entiendo. Sin embargo, los hay, e incluso algunos de ellos son guapos» (Riambau 1996: 90).

Poco podía importar lo que argumentaran «inamistosos» o «amistosos», los informes de culpabilidad estaban escritos de antemano, así como sus despidos por parte de las grandes productoras. Irónicamente, Parnell sería compañero de 
presidio de los injustamente encarcelados por él, al ser acusado y condenado a pena de prisión por malversación de fondos.

El trigésimo cuarto presidente de Estados Unidos de América, Dwight David Eisenhower, llegaría a la Casa Blanca en 1953. El flamante presidente siempre había mostrado su espíritu anticomunista, clamando contra las supuestas políticas filocomunistas de algunos de sus antecesores, especialmente de Rooselvet. Su desprecio también era evidente hacia el mundo de la cultura en general y hacia los intelectuales en particular, sospechosos de ser comunistas por el mero hecho de ser considerados así.

Pero sin lugar a dudas, si hay un nombre que se asocia a la caza de brujas es el de Joseph McCarthy. Espejo (2011: 40-42) opina que el papel de senador de Wisconsin ha sido sobrevalorado al ser erigido como figura más representativa de la persecución, hasta el punto de acuñarse el término «macartismo» para toda la caza. Pero hay que recordar que la actividad de la HUAC precedió y sobrevivió a la carrera política del senador. Pelaz López opina de la misma manera:

A pesar de ser una creencia profundamente extendida, el conocido senador por Wisconsin, Joseph McCarthy, no tuvo nada que ver en todo este proceso. La notoriedad pública del senador arrancó muy posteriormente al inicio de las primeras sesiones (1950) y su actividad se centró en la denuncia de la infiltración comunista en el Departamento de Estado y en el de Defensa. McCarthy no perteneció nunca a la HUAC sino que fue presidente de una subcomisión investigadora del Senado. [...] No obstante, si bien McCarthy jamás puso un pie en Hollywood, el término «macartismo» ha hecho fortuna para definir el fenómeno de la histeria anticomunista en su conjunto, aunque en el mundo del cine este fenómeno se hubiera iniciado tres años antes de la irrupción del senador en escena (2008: 127).

A toda esta tragicómica situación la literatura volvería a responder en la persona del dramaturgo Arthur Miller (2011: 316-318) que, aterrado por la situación, buscaba un texto que reflejara la paranoia anticomunista, pero no daba con la fórmula adecuada para hacerlo hasta que se produjo un afortunado encuentro con un libro:

¿Cómo expresar esto, y mucho más, en un escenario? Empezaba a desesperar de mi propia parálisis. Era un pescador sin anzuelo, un marinero sin vela.

Una tarde afortunada encontré casualmente un libro, El diablo en Massachusetts, de Marion Starkey, un relato de la caza de brujas que tuvo lugar en Salem en 1692. Conocía esa historia por haberla leído en la universidad más de una década atrás, pero ahora, en aquella América cambiada y oscura, descubrí en ella un nuevo aspecto, el de la poesía de la caza. Poesía puede parecer una palabra extraña para hablar de una caza de brujas, pero ahora veía algo maravilloso en el espectáculo de todo un pueblo, si no toda una provincia, cuya imaginación era literalmente presa de algo que no existía (Miller 2011: 318). 
Miller había presenciado, y posteriormente sufrido, los métodos de investigación tanto de Joseph McCarthy como de la HUAC, ambos muy similares. Todos los que comparecían ante la HUAC o la subcomisión del senador eran ya de facto culpables, tanto si confesaban como si se negaban a ello. El simple hecho de acogerse a la quinta enmienda, que exime a todo norteamericano de declarar contra sí mismo, era considerada prueba de su culpabilidad. Las condenas se producían por desacato o por perjurio y solo se podía mostrar arrepentimiento sincero si, después de declararse culpable, se incriminaba a otras personas en la conjura comunista. Cuando el dramaturgo norteamericano se vio inmerso en la lectura de los legajos originales de los juicios de Salem, el paralelismo le fue evidente:

En la silenciosa sala de justicia de Salem rodeado por el torbellino miasmático de las imágenes de los años cincuenta del siglo xx, pero con la mente en 1692, poco a poco fue perfilándose con mayor nitidez lo que ambas épocas tenían en común. En las dos existía la amenaza de las maquinaciones ocultas, pero lo más sorprendente eran las similitudes en los rituales de defensa y los procedimientos rutinarios de investigación. Separadas por trescientos años, ambas persecuciones aducían que los perseguidos pertenecían a un grupo secreto y desleal. En las dos épocas, si el acusado confesaba, su sinceridad se demostraba de una única e idéntica manera, nada menos que nombrando a los antiguos cómplices. De esta manera el informador se convertía en la prueba misma de la maquinación y de la necesidad de la investigación.

Finalmente, en ambos periodos, dado que el enemigo era ante todo una idea, la prueba de haber cometido acciones desleales o perdían importancia o se dejaban en el limbo, o no se requería en absoluto. Y, en efecto, al final las acciones eran por completo irrelevantes; al final, la sola sospecha casi se convertía en la prueba de la deslealtad (Miller 2011: 320).

Para la redacción de la obra, Miller tardó más de un año, ya que se documentó con las actas judiciales reales de Salem incluyendo algunos fragmentos de las mismas casi de manera literal, lo que le da a la obra teatral un valor histórico añadido. Mientras que redactaba la obra Miller se dio cuenta de la pertinencia de Salem como metáfora de lo que él mismo estaba sufriendo:

Más que una metáfora política, más que un cuento moral, Las brujas de Salem, tal como fui desarrollándola durante más de un año, se convirtió en una imponente evidencia del poder de la imaginación humana inflamada, la poesía de la insinuación y, finalmente, la tragedia de la resistencia heroica a una sociedad poseída hasta el extremo de labrarse su ruina (Miller 2011: 320).

Cuando la obra fue estrenada el 22 de enero de 1953 en el teatro Martín Beck de Nueva York, tanto público como crítica se dieron cuenta de la fuerte denuncia 
implícita hacia la situación política de su país, lo que la llevó a un absoluto fracaso comercial:

En el aspecto comercial, la obra fue, desde luego un fracaso. Para empezar, el título: nadie sabía qué era un crisol. La mayoría de los críticos, como sucede a veces, no comprendieron la ironía que subyace en la obra, y a los que sí la comprendieron les ponía nerviosos aprobar una obra tan dura con los mismos principios básicos en los que se apoyaba la caza de rojos que tenía lugar por entonces y que nadie osaba criticar. La noche del estreno, viejos conocidos me evitaron en el vestíbulo del teatro, e incluso sin aire acondicionado la atmósfera de la sala era notablemente fría (Miller 2011: 324).

A pesar de que el «terror rojo» estaba en franco declive en 1955, fue cuando Miller comenzó a sufrir la persecución. La HUAC languidecía y cuando Miller anunció su matrimonio con Marilyn Monroe, vieron en el dramaturgo una manera de reverdecer su popularidad en un esperpéntico proceso, donde el presidente del comité que debía enjuiciar a Miller - Francis Walter - le propuso olvidar todo el asunto a cambio de realizarse una foto con la actriz. Tras la negativa del acusado, este fue condenado a una pena de cárcel que después se conmutó por una multa en metálico, sin que en el proceso Miller doblegara su voluntad. Tan solo tres años después, Estados Unidos le concedería la medalla de oro del National Institute of Art and Letters. La caza de brujas había finalizado y lo único que a día de hoy pervive es, irónicamente, su obra de teatro ya que como se dio cuenta Miller, la caza de brujas es algo atemporal y universal:

Las brujas de Salem es mi obra que más veces se ha llevado a los escenarios, tanto en Estados Unidos como en el extranjero. Parece ser que uno de los pocos fragmentos del llamado periodo maccarthista que sobrevive. Y creo que un aspecto notable de esta obra es que la gente, en muy diversos lugares del mundo, considera como propia la historia que cuenta. [...] Similares reacciones he observado en rusos, sudafricanos, latinoamericanos y gentes de todas las nacionalidades que han soportado dictaduras, tan universal es la metodología del terror representada en Las brujas de Salem. De hecho, solía pensar yo medio en serio, aunque no estaba lejos de la verdad, que uno podía saber que un dictador estaba a punto de hacerse con el poder en un país latinoamericano o que otro acababa de ser derrocado si de repente Las brujas de Salem se representaba en el país (Miller 2011: 326).

Como en Salem, muchos de los acusadores o participantes en tan ominosa caza pidieron perdón posteriormente. Este es el caso del actor y presidente de los Estados Unidos, Ronald Reagan, que declararía que «hubo una parte oscura en esta batalla: fue una historia de víctimas y no solo de villanos. [...] Mucha gente muy buena se vio falsamente acusada de ser comunista por ser simplemente liberal» (1991: 117-118). 


\section{De los escenarios teatrales a las pantallas}

Muchos fueron los cineastas que valoraron el potencial de la obra de Miller para la pantalla. En 1957 se estrenó Les sorcières de Salem bajo la dirección de Raymond Rouleau y guion de Marcel Aymé y Jean-Paul Sartre 4 . En 1967, Alex Segal firmaba su versión televisiva, The crucible, que ganó un Emmy ese mismo año. La España franquista, irónicamente, tuvo también su versión televisiva en 1965 con Las brujas de Salem, dirigida por Pedro Amalio López y con un elenco de lujo con nombres tales como Irene Gutiérrez Caba, Gemma Cuervo o Antonio Ferrandis $^{5}$. No sería la única; en 1973 el mismo director repetiría con otro reparto estelar capitaneado en esta ocasión por Concha Velasco ${ }^{6}$. A pesar de todos estos antecedentes, Miller se negaba a trabajar en un guion de su propia obra teatral dados sus recelos ante el mundo del cine:

Dado que mis primeras tentativas literarias fueron ya obras teatrales, llegué a creer que en una edad todavía temprana que el cine, en el caso de que fuera arte más que artesanía, pertenecía en todo caso a una categoría inferior. [...] durante mi adolescencia y primera juventud, cuando el cine fue definiéndose para mí, casi todas las películas que veía se me antojaban puras trivialidades cuya finalidad, incluso para alguien tan ingenuo como yo, no era otra cosa que ganar dinero con unas cuantas risas o lágrimas o sustos como principal condimento. [...] Las películas no tenían ideas, sólo acción. A medida que uno adquiría una visión más seria de la vida, volvía la vista hacia el teatro en busca de algo que le ayudara a entenderla mejor, y en el teatro encontraba uno prestigiosas obras escritas a lo largo de los siglos [...] a mí me seguía resultando imposible atribuir al cine una auténtica finalidad artística (Miller 2013: 165).

A pesar de estas reticencias, Miller se avino a escribir un guion cinematográfico junto con el también dramaturgo y director de cine Nicholas Hytner, para una

$4 \quad$ Ficha técnica de la película: Título original: Les sorcières de Salem. Año: 1957. Duración: 145 min. País: Francia. Director: Raymond Rouleau. Guion: Marcel Aymé, Jean-Paul Sartre (Obra: Arthur Miller). Música: Georges Auric, Hanns Eisler. Fotografía: Claude Renoir. Reparto: Simone Signoret, Yves Montand, Mylène Demongeot, Alfred Adam, Jean Debucourt, CoutanLambert, Aribert Grimmer, Pascale Petit, Michel Piccoli. Productora: Coproducción FranciaAlemania del Este. Género: Drama | Histórico. Siglo XviI. Brujería. Fuente: Filmaffinity

5 Las brujas de Salem. Director: Pedro Amalio López; intérpretes: Irene Gutiérrez Caba, Gemma Cuervo, Antonio Ferrandis, Lola Gaos, Pastor Serrador, Francisco Piquer, Tina Sainz, etc.; emisión: TVE, 22 de febrero de 1965 (otra emisión en 1978); programa: Estudio 1; género: Teatro-Representación (Mateo Martínez-Bartolomé 2000: 154).

6 Las brujas de Salem. Director: Pedro Amalio López; intérpretes: Concha Velasco, Berta Riaza, Fernando Delgado, Luis Prendes, Tina Sainz, Carlos Lemos, etc.; emisión: TVE, 11 de mayo de 1973; programa: Estudio 1; género: Teatro-Representación (Mateo Martínez-Bartolomé 2000: 154). 
adaptación de su obra que se estrenó en $1996^{7}$, lo que hizo cambiar de idea a Miller sobre el cine cuando descubrió que este anulaba las limitaciones de escenario del teatro y que «sería posible salir a las calles de Salem, sitios a los que la obra teatral solo llega por referencia» (Miller 2013: 167).

Lo más interesante del guion cinematográfico es que su autor es el mismo que el de la obra teatral, un autor consciente de estar escribiendo para otro medio visual totalmente distinto, razón por la que introdujo importantes cambios sin desvirtuar el espíritu de su obra (Guelvenzu 1997), dando lugar a un nuevo texto sobre la intolerancia y el fanatismo; un relato que pone al día para el espectador una enseñanza que nos obcecamos en olvidar sin darnos cuenta de que las llamas de Salem están prestas a prender de nuevo en cualquier lugar como ya hemos reflejado.

¿Puede tener el guion teatral y cinematográfico un valor didáctico e incluso un elemento de reflexión histórica? Esta cuestión no es en absoluto nueva, ya el director D. W. Griffith, uno de los padres del lenguaje fílmico, afirmaba en 1915 que «Llegará un momento en que a los niños de las escuelas se les enseñará prácticamente todo a través de las películas: nunca se verán más obligados a leer libros de historia» (Caparrós Lera 1997: 25). Afirmación más que controvertida pero que encierra la esencia de la relación tempestuosa entre cine e historia - que entró en el ámbito académico gracias a entre otros Marc Ferro, Sorlin o Rosentone- imposible de abordar en los límites del presente trabajo.

El cine ha seducido a muchos historiadores por su poder evocador, por ejemplo, a la norteamericana Natalie Zemon Davis, que «soñaba con un ejemplo jugoso que me permitiera actuar como antropóloga observando la experiencia cotidiana, en lugar de realizar un recuento basado en un registro tributario aquí y un contrato matrimonial allá» (2012: 12). El sueño se cumplió cuando la historiadora se enfrentó a un caso de la Francia de 1560, donde un hombre se hizo pasar por otro - Martín Guerre - , durante nada menos que tres años a ojos de todo un pueblo y cohabitando incluso con su esposa. Lo espectacular del caso hizo que la historiadora valorara sus posibilidades cinematográficas y, entre 1980 y 1982, sirvió de asesora al director Daniel Vigne y al guionista Jean-Claude Carriere para la elaboración del filme El regreso de Martín Guerre:

Ver a Depardieu interpretando al impostor Arnaud du Thil fingiendo ser Martin Guerre me brindó nuevas preguntas que formular en relación con la definición del

7 Título original: The Crucible. Año: 1996. Duración: 123 min. País: Estados Unidos Estados Unidos. Director: Nicholas Hytner. Guion: Arthur Miller. Música: George Fenton. Fotografía: Andrew Dunn. Reparto: Daniel Day-Lewis, Winona Ryder, Paul Scofield, Joan Allen, Bruce Davison, Rob Campbell, Jeffrey Jones, Peter Vaughan, Karron Graves, George Gaynes, Charlayne Woodard, Frances Conroy, Elizabeth Lawrence, Rachael Bella. Productora: 20th Century Fox. Género: Drama | Siglo XVII. Brujería. Fuente: Filmaffinity. 
ser en la Francia del siglo XVI. Fue entonces que comencé a pensar en el cine histórico como «experimento del pensamiento». Junto con los archivos del XVI de la aldea de Martin Guerre en Artigat, teníamos la aldea en que filmábamos... un Artigat sustituto donde podíamos poner a prueba el pasado (Zemon Davis 2012: 13).

Este acercamiento al cine, a pesar de sus bondades, no escondía para la historiadora los límites del mismo a la hora de armar un discurso histórico, lo que llevó a la misma a la redacción de un ensayo histórico homónimo a la película (Zemon Davis 2013), trabajo que se ha convertido en paradigmático para sondear en las relaciones entre historia y cine. Hay notables diferencias entre narrar una historia en prosa y hacerlo en cine, pero con trabajo y paciencia la narración histórica en el cine podría hacerse más dramática y más fiel a las fuentes del pasado.

\section{Conclusiones}

Entendemos el enorme potencial que tiene la literatura, ya sea como guion teatral o cinematográfico contenido en la obra de Miller, no solo como «experimento del pensamiento» a la manera de Zemon Davis, sino como forma de acercar la historia al espectador. A esta tesis se podría oponer que los guiones de Miller son literatura y por tanto no son reales, pero si aceptamos tal extremo deberíamos rechazar todos los libros de demonología y actas judiciales pues, como toda fuente histórica, está empapada de literatura. Es más, los escritos históricos, aún basándose en la realidad y en el método historiográfico que le da validez científica, contienen mucha más literatura de lo que algunos historiadores están dispuestos a reconocer. Los textos de brujería y demonología debemos considerarlos literatura, pues de no hacerlo estaríamos valorando la posibilidad real de que el demonio trotara por los bosques en reuniones a las que brujas y brujos acudirían volando en sus escobas. Esto no les quita un ápice de realidad, pues como hemos visto, estos textos tuvieron un efecto dolorosamente real en el mundo físico.

Unos textos de extrema y cruda realidad que siguen vigentes en nuestro mundo como se dio cuenta Robert Eggers, el director de La bruja (2015), cuando en sus notas de guion dejó escrito: «Las sombras de Salem están vivas en el inconsciente actual. [...] Seguimos atrapados en ciclos de pensamiento realmente regresivos y feos. La bruja representa las sombras de lo desconocido, y la gente aún la señala con un dedo acusatorio» (Piña 2016). La actualidad y universalidad de Salem tampoco se le escapó al director de El Crisol (1996), Nicholas Hytner:

[...] nos vimos sorprendidos una y otra vez por su alarmante actualidad, ya que hablaba directamente del fanatismo de los fundamentalistas religiosos de todo el mundo, de las comunidades desgarradas por las acusaciones de abuso sexual infantil, 
de las rígidas ortodoxias intelectuales de las universidades; es evidente que en el mundo contemporáneo no escasean los Salems dispuestos a gritar: «¡Brujería!». Pero la película no contiene referencias políticas concretas. Las brujas de Salem ha sobrevivido a Joe McCarthy, y ha ido adquiriendo una dimensión universal sólo compartida por otras historias que hablan de verdades elementales (2013: 170).

No encontramos mejor epílogo para reivindicar la importancia del estudio y lectura de todo el material que generaron los procesos de Salem. Desde los libros que sirvieron para justificarla a las obras de Miller basadas en unas actas judiciales disponibles para todo el mundo hoy gracias a internet. Obviamente no estamos en un momento histórico para olvidar lecciones sobre intolerancia. La vida de muchas personas, y no de manera metafórica, puede depender de ello. 


\section{BIBLIOGRAFÍA}

Azurmendi, Mikel (2012). «A vueltas con el término aquelarre». En Jesús María Usunáriz Garayoa (ed.), Akelarre: la caza de brujas en el Pirineo (siglos XIII-XVIII). RIEV. Revista Internacional de los Estudios Vascos, 9, pp. 42-53.

Bosch, Rafael (1984). «El asesinato de las brujas de Salem: en nombre de Dios y del poder». Historia 16, 97, pp. 73-84.

Boyer, Paul y Stephen Nissenbaum (1972). Salem-Village Witchcraft. A Documentary Record of Local Conflict in Colonial New Englang. Boston: Northeastern University Press.

Boyer, Paul (1974). Salem Possessed: The Social Origins of Witchcraft. Cambridge MA: Harvard University Press.

Bratle, Thomas (1914). «Letter of Thomas Bratle» [1692]. En George Lincoln Burr (ed.), Narratives of the Witchcraft cases (1648-1706). New York: Charles Scribner's Sons, pp. 169-176.

CAPARrós Lera, José María (1997). «Autopercepción intelectual de un proceso histórico: autobiografía intelectual». Revista anthropos: Huellas del conocimiento, 175, pp. 9-31.

Castañega, fray Martín de (1994). Tratado de las supersticiones y hechizerías y de la possibilidad y remedio dellas [1529]. Juan Robert Muro Abad (ed.). Logroño: Instituto de Estudios Riojanos.

ESPEJo Romero, Ramón (2011). «Introducción». En Arthur Miller, El crisol. Madrid: Cátedra, pp. 9-108.

FERnÁndez JuÁrez, Gerardo (2016). «Animismo y brujería caribeños en El crisol (1996) de Nicholas Hytner». En María Jesús Zamora Calvo (ed.), Brujas de cine. Madrid: Abada editores, pp. 219-245.

Ginzburg, Carlo (2003). Historia nocturna. Las raices antropológicas del relato. Barcelona: Península.

Golubov, Nattie (2004). «Salem, 1692». Coloquio interdisciplinario sobre brujas. México: Facultad de Filosofía y Letras UNAM, pp. 45-54.

Henningsen, Gustav (2012). «El invento de la palabra Aquelarre». En Jesús María Usunáriz Garayoa (ed.), Akelarre: la caza de brujas en el Pirineo (siglos XIIIXVIII). RIEV. Revista Internacional de los Estudios Vascos, 9, pp. 56-65.

Howe, Katherine (ed.) (2016). El libro de las brujas. Casos de brujería en Inglaterra y en las colonias norteamericanas (1582-1813). Barcelona: Alba.

Hytner, Nicholas (2013). «El rodaje de El Crisol». En Arthur Miller, Las brujas de Salem y el Crisol. Barcelona: Tusquets, pp. 169-181.

Lancre, Pierre de (2004). Tratado de brujería vasca. Descripción de la inconstancia de los malos ángeles y demonios [1613]. Elena Barberena (ed.). Tafalla: Txalaparta.

LeVACK, Brian. P. (1995). La caza de brujas en la Europa Moderna. Madrid: Alianza. 
Mateo Martínez-Bartolomé, Marta (2000). «Las brujas de Salem y El crisol: las versiones españolas de la obra de A. Miller en el teatro, TV y cine». Quaderns. Revista de traducció, 5, pp. 147-160.

MÉndEZ, Agustín (2015). «Demonios reformados. Providencia, tentación e internalización del mal en las demonologías de George Gifford, William Perkins y Richard Bernard». Espacio, tiempo y forma, 28, pp. 237-258.

MÉNDEZ, Agustín (2018). «El pastor y el martillo. Aproximación comparativa a los tratados demonológicos de Thomas Cooper y Heinrich Krämer». Studia historica. Historia moderna, 40, 1, pp. 299-330.

Miller, Arthur (2011). Al correr de los años. Barcelona: Tusquets.

MilLER, Arthur (2011). El crisol. Madrid: Cátedra.

MilLER, Arthur (2013). «Notas sobre la versión cinematográfica de Las brujas de Salem». En Arthur Miller, Las brujas de Salem y El crisol. Barcelona: Tusquets, pp. 165-168.

Pelaz López, José Vidal (2008). «Cae el telón. El cine norteamericano en los inicios de la Guerra Fría». HAOL, 15, pp. 125-136.

PIÑA, Begoña (2016). «Robert Eggers: Incluso si Dios y el diablo son reales, la histeria religiosa existe». Diario Público Digital <http://www.publico.es/culturas/diosdiablo-histeria-religiosa-bruja.html $>$ [Consulta: 14-08-2018].

Reagan, Ronald. (1991). Una vida americana. Barcelona: Plaza y Janés / Cambio 16.

Riambau, Esteve (1996). «La posguerra y el Maccarthysmo». En Esteve Riambau (ed.), Historia General del Cine. Estados Unidos (1932-1955). Madrid: Cátedra, vol. VII, pp. 81-118.

TAusiet, María (2010). «Razonar lo irracional: una conversación con Stuart Clarck». Historia Social, pp. 159-172.

Zamora Calvo, María Jesús (2002). «Reflejos de mundos ocultos. Inquisidores y demonólogos en los Siglos de Oro». En María Luisa Lobato y Francisco Domínguez Matito (eds.), Memoria de la palabra. Madrid / Frankfurt a. M.: Iberoamericana / Vervuert, vol. II, pp. 1885-1895.

Zamora Calvo, María Jesús (2016). Artes Maleficorum. Brujas, magos y demonios en el Siglo de Oro. Barcelona: Calambur.

Zemon Davis, Natalie (2012). Esclavos en la pantalla. La Habana: ICAIC.

Zemon Davis, Natalie (2013). El regreso de Martín Guerre. Madrid: Akal.

Recibido: 04/09/2018

Aceptado: 20/09/2018 


\section{(2) \\ BRUJAS, LIBROS Y CINTAS DE VÍDEO: \\ LITERATURA EN TORNO A LOS JUICIOS DE SALEM}

RESUMEN: Las pruebas que tenemos en torno a la brujería, el aquelarre y el pacto demoniaco parecen indicarnos que nos encontramos ante un delito inventado en gran parte por una elite. Un delito que nace de los libros de los inquisidores y los tratados de magia que dieron cobertura legal a la caza de brujas que se desarrolló en occidente principalmente entre finales del XV y finales del XVII.

Los hechos acaecidos en Salem en 1692 no pueden entenderse sin los tratados demonológicos que le precedieron y los escritos que se generaron posteriormente. Entendemos que cualquier escrito está obligado a crear un argumento, por lo que valoraremos la utilidad histórica de los escritos más relevantes del proceso: desde las actas judiciales hasta el guion cinematográfico de la película $\mathrm{El} \mathrm{crisol,} \mathrm{basada} \mathrm{en} \mathrm{la} \mathrm{obra} \mathrm{teatral} \mathrm{homónima} \mathrm{de}$ Arthur Miller.

Palabras clave: Salem, brujería, Arthur Miller, El crisol, cine, teatro.

\section{WITCHES, BOOKS AND VHS TAPES: \\ LITERATURE ABOUT THE SALEM TRIALS}

ABSTRACT: All evidence we have about Witchcraft, Witches'Sabbath and Demonic Covenant seems to point out that it was nothing but a crime that was invented mostly by an elite. A crime that was born from the Enquirers' books as well as from the Magic Treatises that gave legal coverage to the Witches' Hunt that took place on the Western World mainly at the end of the 15th and 17th centuries.

The facts that took place in Salem on the year 1692 cannot be understood without the study of the previous Demonic Treatises and the documents written afterwards. We understand that any document has to create a plot, so we will analize the historical relevance of the most important documents about that fact, from the records from the court hearings to the script from the film The Crucible based upon the play of the same title written by Arthur Miller.

KEYWORDS: Salem, witchcraft, Arthur Miller, The Crucible, cinema, theater. 


\section{Edad de Oro. Revista de Filología Hispánica}

ISSN: 0212-0429 - ISSNe: 2605-3314 <https://revistas.uam.es/edadoro/index>

Edad de Oro es uno de los máximos referentes en el área de investigación en Filología Hispánica, especialmente de los siglos XVI y XVII. Goza de un amplio reconocimiento en el ámbito académico internacional. Desde 1982 publica ininterrumpidamente, con una periodicidad anual, colaboraciones científicas de los principales especialistas de diversos centros nacionales y extranjeros. Con un público compuesto esencialmente por investigadores y expertos de todo el mundo, se dirige a cualquier persona interesada en las nuevas corrientes de los estudios humanísticos de su campo.

Dirección:

María Jesús Zamora Calvo

(Univ. Autónoma de Madrid)

Subdirección:

José Antonio Llera Ruiz

(Univ. Autónoma de Madrid)

Secretaría:

Raquel Arias Careaga

(Univ. Autónoma de Madrid)

Consejo de redacción:

Cecilia López-Ridaura

(ENES. Morelia / Univ. Nacional

Autónoma de México)

José Luis Ocasar Ariza

(Univ. Autónoma de Madrid)

Rocío Pérez Gironda

(Univ. Autónoma de Madrid)

Carolina Fernández Cordero

(Iberoamericana-Vervuert)

Admisión de originales:

María Jesús Zamora Calvo

Edad de Oro

Universidad Autónoma de Madrid

Facultad de Filosofía y Letras

Departamento de Filología Española

Campus Cantoblanco

28049 Madrid (España)

Tfno. (+34) 914976886

Correo-e: mariajesus.zamora@uam.es

Distribución, suscripción y venta:

Servicio de Publicaciones de la UAM

Universidad Autónoma de Madrid

28049 Madrid (España)
Intercambio de publicaciones:

Biblioteca de Humanidades

Universidad Autónoma de Madrid

28049 Madrid (España)

Comité científico:

Carlos Alvar (Université de Gèneve)

Ignacio Arellano (Univ. de Navarra)

Alberto Blecua

(Univ. Autónoma de Barcelona)

Jean Canavaggio

(Université Paris Nanterre)

Aurora Egido (Univ. de Zaragoza)

Víctor García de la Concha (RAE)

Luciano García Lorenzo (CSIC)

Joaquín González Cuenca

(Univ. de Castilla la Mancha)

Agustín de la Granja López

(Univ. de Granada)

Begoña López Bueno (Univ. de Sevilla)

Michel Moner

(Universitè Toulouse - Jean Jaurès)

Joan Oleza (Univ. de Valencia)

Alfonso Rey

(Univ. de Santiago de Compostela)

Lina Rodríguez Cacho

(Univ. de Salamanca)

Leonardo Romero Tobar

(Univ. de Zaragoza)

Aldo Ruffinatto

(Università degli Studi di Torino)

Lía Schwartz

(City University of New York)

Han colaborado en este volumen:

Departamento de Filología Española

(UAM)

Facultad de Filosofía y Letras (UAM)

Edad de Oro se recoge en las siguientes bases de datos y directorios: DICE; HLAS; MLA International Bibliography; PIO; ISOC-CSIC; DIALNET; SUMARIS CBUC; ULRICH'S.

Se encuentra evaluada en: SCOPUS: Q2; SCImago: SJR 2017 0.11, H Index 4; ERIH Plus: category A; CIRC: categoría C; RESH: 0.162; MIAR: ICDS 2017 10.0; CARHUS Plus+: C; LATINDEX. 


\section{EDAD DE ORO}

Revista de Filología Hispánica XXXVII

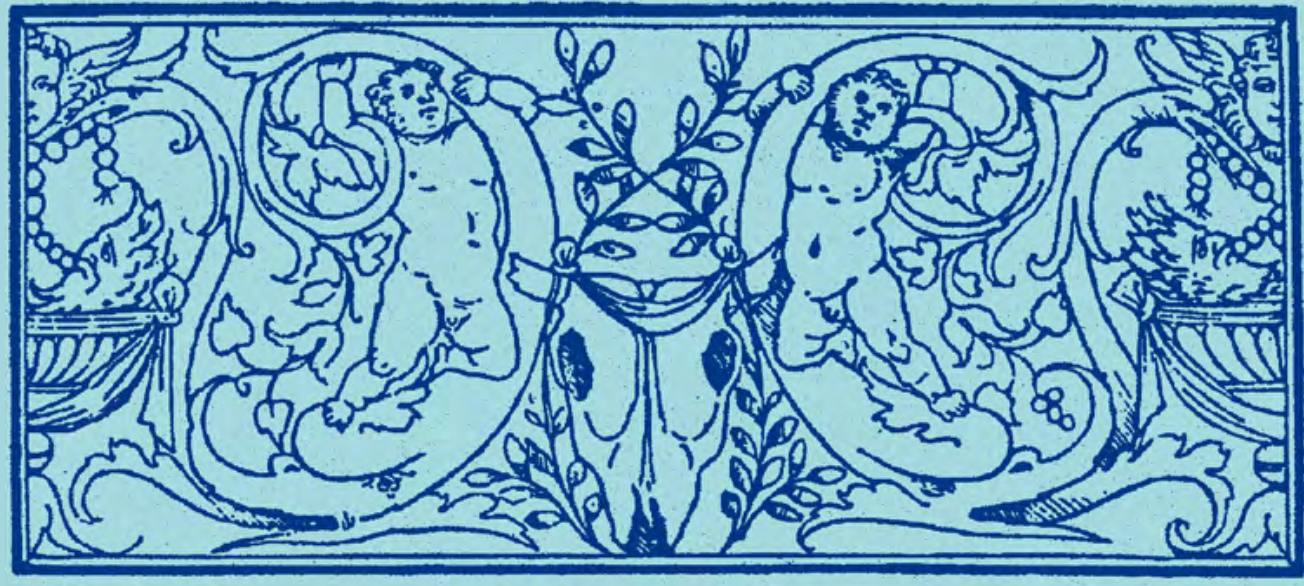

\section{DEPARTAMENTO DE FILOLOGÍA ESPAÑOLA}

EDICIONES DE LA UNIVERSIDAD AUTÓNOMA DE MADRID 